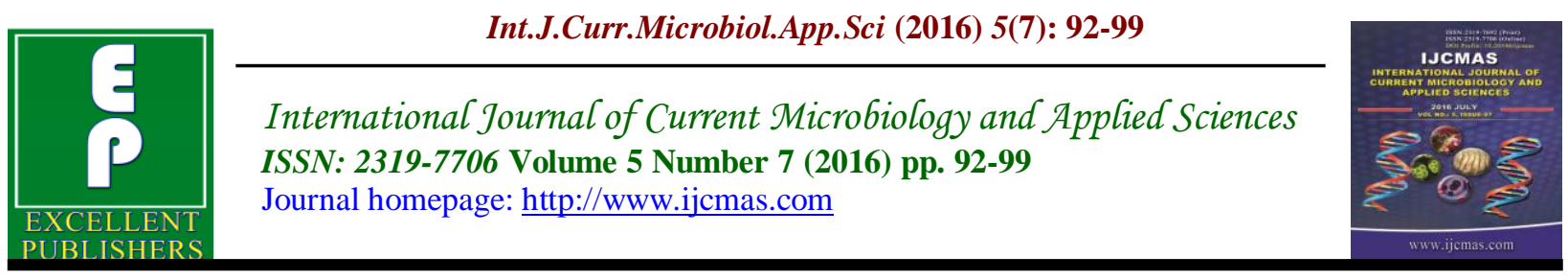

Original Research Article

http://dx.doi.org/10.20546/ijcmas.2016.507.007

\title{
Studies on Soil Mycoflora in Different Tomato fields of Four Districts in Tamil Nadu, India
}

\author{
A. Paulina Fatima Mary ${ }^{1}$ and R. Sagaya Giri ${ }^{2}$ \\ Department of Botany, Kunthavai Naacchiyaar Government Arts College for Women \\ (Autonomous), Thanjavur-7, India \\ *Corresponding author
}

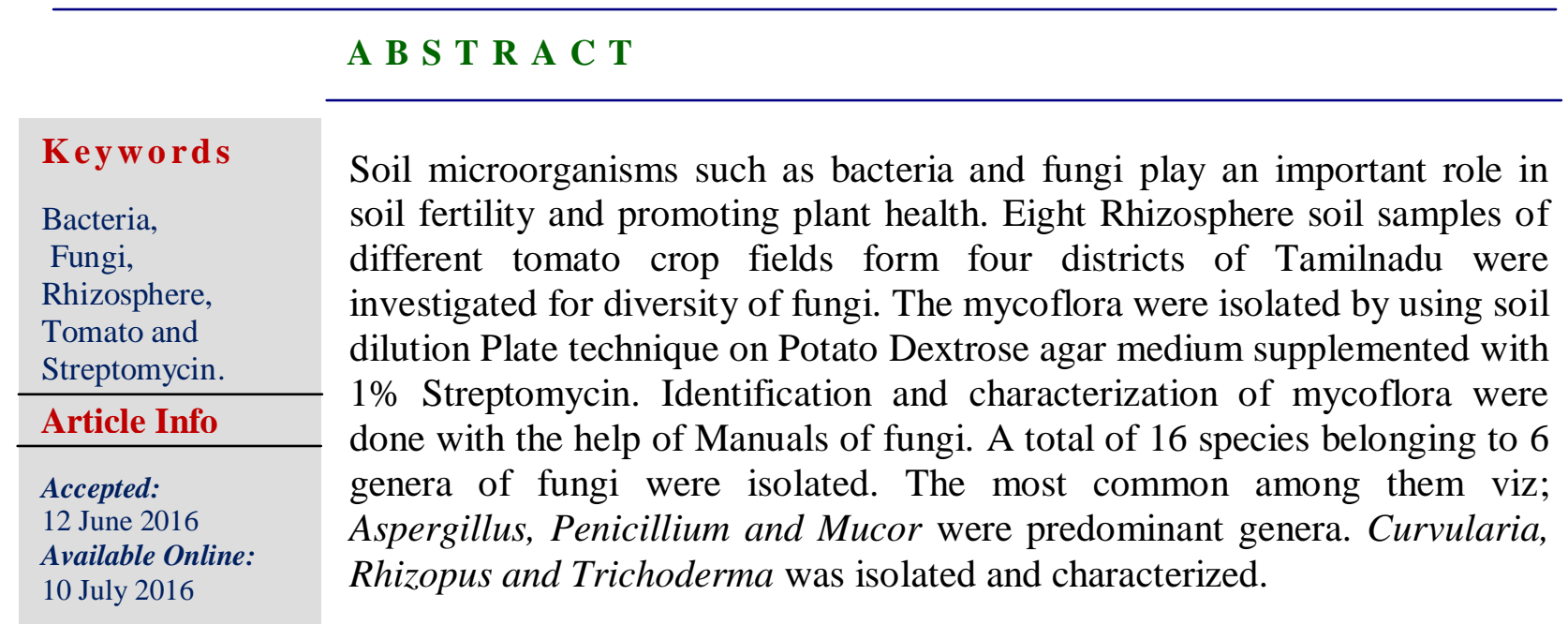

\section{Introduction}

Soils are highly complex systems, with many components playing diverse functions mainly due to the activity of soil organisms (Chiang et al., 1994). Soil microflora plays a pivotal role in evaluation of soil conditions and in stimulating plant growth (Kiran Singh et al.,1999). Microorganisms are beneficial in increasing the soil fertility and plant growth as they are involved in several biochemical transformation and mineralization activities in soils. Type of cultivation and crop management practice found to have greater influence on the activity of soil microflora (Mc. Gill et al., 1980). The rhizosphere is the narrow region of soil that is directly influenced by root secretions and associated soil microorganisms. The rhizosphere microorganisms predominantly help in metabolizing the root exudates. Microorganisms in the Rhizosphere complete both chemical and physical modifications to the soil profile in and around the rhizosphere that affect plants. They can be beneficial to the plant (by pathogen suppression) or detrimental (by competition for nutrients) (Sylvia et al., 2005). Fungi are an important component of the soil microbiota typically constituting more of the soil biomass than bacteria, depending on soil depth and nutrient conditions (Ainsworth and Bishy, 
1995). The role of fungi in the soil is an extremely complex one and it is fundamental to the soil ecosystem. They perform ecological services that strongly impact the quality of human life and have enormous potential for providing economic benefits. Microfungi play a focal role in nutrient cycling by regulating soil biological activity (Arunachalam et al., 1997). The quantities of organic and inorganic materials present in the soil have a direct effect on the fungal population of the soil.

The members and kinds of microorganisms present in soil depend on many environmental factors such as the amount and type of nutrients, moisture, aeration, $\mathrm{pH}$ and temperature etc. The aim of the present investigation is to isolate mycoflora from different tomato fields and to observe the percentage contribution of different fungal species.

\section{Materials and Methods}

\section{Collection of soil samples}

Rhizosphere soil samples were collected from different tomato field of various Districts in Tamil Nadu (S1, S2, S3, S4, S5, S6, S7 and S8) Table-1. In each field $1 \mathrm{~kg}$ of soil sample was collected from the surface area reaching about $10-15 \mathrm{~cm}$ depth and near the rhizosphere region of plants. Soils were collected in sterile polythene bags and sealed on the spot. Samples were stored in laboratory at $4^{0} \mathrm{C}$ until further analysis.

\section{Isolation of Mycoflora}

Dilution plate technique described by Warcup (1955) was used for the isolation of fungi from various rhizosphere soil samples. 10 grams of soil samples were suspended in $90 \mathrm{ml}$ of distilled water. The flasks were shaken thoroughly in order to get uniform distribution of the soil particles. The soil suspensions were diluted in 10 fold increment from $10^{-2}$ to $10^{-4}$. The Volume of $10 \mathrm{ml}$ of soil sample suspension from each serial dilution was pipetted onto different melted, cooled culture media Potato Dextrose Agar (PDA) supple- mented with $1 \%$ Streptomycin. The $\mathrm{pH}$ of the culture media was maintained at 5.5 being optimal for the growth and sporulation in a majority of fungi. Each culture media was prepared in a liter of distilled water and autoclaved at $120^{\circ} \mathrm{C}$ at $15 \mathrm{psi}$ for $20 \mathrm{~min} .1 \%$ Streptomycin was used as an antibiotic for the restrain of bacterial growth. Each colony was sub cultured and maintained on potato dextrose agar slants. The inoculated plates were incubated at room temperature $28 \pm 2^{\circ} \mathrm{C}$ in an inverted position for 5-7 days. Three replicates were maintained for each sample.

\section{Pure Culture and identification}

Purification of the fungi was made by single spore culture method. A portion of the growing edge of each colony was picked up with the help of a pair of needles and mounted on a clean slide with lactophenol cotton blue. The slide was gently heated over the flame so as to remove air bubbles. The excess stain was wiped off with the help of tissue paper and then the cover slip was sealed with transparent nail polish for semi permanent. The slide was observed under microscope and microphotographs of the individual fungal species were also taken using Nikon Microscope. Identification of the organisms were made with the help of Manual of soil fungi (Gillman, 2001).

\section{Statistical analysis}

The number of colonies per plate in $1 \mathrm{~g}$ of soil was calculated. The percent contribution of each isolate was calculated by using the following formula: 


\author{
Total No. of CFU* of an \\ individual species \\ $\%$ Contribution $=-100$ \\ Total No. of CFU* of \\ all species \\ *CFU-Colony forming Unit
}

\section{Physicochemical analysis of soil samples}

The collected soil samples ware dried in aseptically at laboratory for characterization of physico-chemical properties. Physical and chemical parameters of soil such as $\mathrm{pH}$, salinity, soil texture, organic carbon, nitrogen, phosphorus, potassium were analyzed. The physico-chemical parameters of the soil samples were analyzed at Dr. M. S. Swaminathan Research Foundation, Thiruvaiyaru, Thanjavur District, Tamilnadu.

\section{Results and Discussion}

Fungi are an important component of the soil microbiota typically constituting more of the soil biomass than bacteria, depending on soil depth and nutrient conditions. The saprophytic fungi represent the largest proportion of fungal species in soil and they perform a crucial role in the decomposition of plant structural polymers, such as cellulose, hemicelluloses and lignin, thus contributing to the maintenance of global carbon cycle. In the present study 181 fungal colonies of 16 fungal species were isolated from different tomato fields of various Districts in Tamil Nadu.

The maximum fungal species belonging to Ascomycets (156 colonies) and Zygomycetes (25 colonies) were observed. Apergillus, Penicillium and Mucor species were the dominant fungal species found among the isolates. Diversity was found to be higher in the tomato fields of Thanjavur and Thiruvaur districts when compared to the other districts (Table-2).

They are dependent on the nature of substrate and temporal region that favors the colonization, growth and substrate possession of the fungi (Rani et al., 2010). The soil mycoflora in different tomato fields viz; S1, S2, S3, S4, S5, S6, S7 \& S8 were observed. The highest contribution among them Viz; Aspergillus flavus (21.43\%), Penicillium notatum (18.75\%) Aspergillus niger (17.86\%), Penicillum chrosogenum (17.4\%) and Aspegillus terreus (15.79\%) were isolated and identified (Table-3).

Table.1 Collection of soil samples

\begin{tabular}{|c|l|l|}
\hline $\begin{array}{c}\text { Soil } \\
\text { Sample }\end{array}$ & Districts & \multicolumn{1}{c|}{ Places } \\
\hline S1 & \multirow{2}{*}{ Thanjavur } & Arputhapuram \\
S2 & & Nagathi \\
\hline S3 & \multirow{2}{*}{ Tiruvarur } & Vaduvur \\
S4 & & Edamalaiyur \\
\hline S5 & \multirow{2}{*}{ Pudukkottai } & Vennavalkudi \\
S6 & & Annai Nagar \\
\hline \multirow{2}{*}{ S7 } & \multirow{4}{*}{ Ariyalur } & $\begin{array}{l}\text { Thanrayappan } \\
\text { Mettutheru }\end{array}$ \\
& & Allinagaram \\
\hline S8 & & \\
\hline
\end{tabular}


Table.2 Occurrence of soil mycoflora in different tomato field from various Districts of Tamilnadu

\begin{tabular}{|c|c|c|c|c|c|c|c|c|c|c|c|c|c|c|c|c|c|c|}
\hline \multirow[b]{3}{*}{ 葛 } & \multirow[b]{3}{*}{ 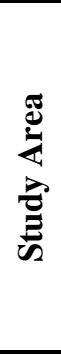 } & \multicolumn{17}{|c|}{ Average No. of Individual Colonies } \\
\hline & & \multicolumn{8}{|c|}{ Aspergillus Species } & \multicolumn{4}{|c|}{ Penicillium Species } & \multirow[b]{2}{*}{ 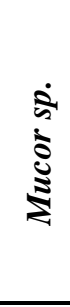 } & \multirow[b]{2}{*}{ 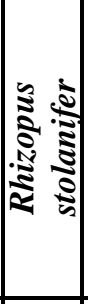 } & \multirow[b]{2}{*}{ 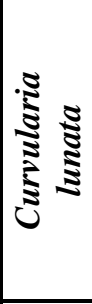 } & \multirow[b]{2}{*}{ 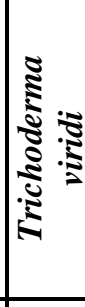 } & \multirow[b]{2}{*}{ 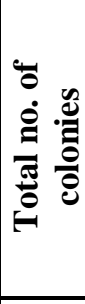 } \\
\hline & & 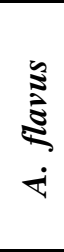 & 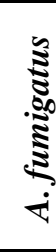 & $\begin{array}{l}\grave{\Xi} \\
\stackrel{\$}{\Xi} \\
\dot{\nabla}\end{array}$ & 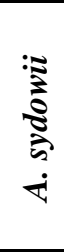 & 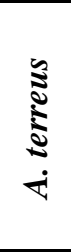 & 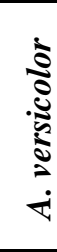 & 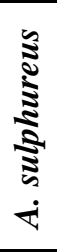 & 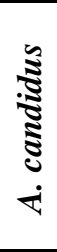 & 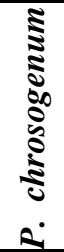 & 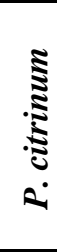 & 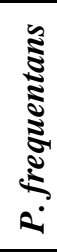 & 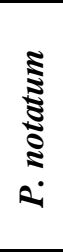 & & & & & \\
\hline \multirow{2}{*}{ Thanjavur } & S1 & 1 & 3 & 5 & 2 & 1 & 2 & 1 & 2 & 2 & 1 & 1 & 1 & 2 & 2 & 1 & 1 & 28 \\
\hline & S2 & 2 & - & 2 & 1 & 2 & 1 & 2 & 1 & 4 & 2 & 1 & 1 & 1 & 2 & 1 & - & 23 \\
\hline \multirow{2}{*}{ Thiruvarur } & S3 & 1 & 2 & 3 & 1 & 3 & 1 & - & 1 & 3 & 1 & - & 2 & 4 & 2 & 2 & 1 & 27 \\
\hline & S4 & 2 & 4 & 3 & 2 & 2 & 2 & 2 & 2 & 2 & 2 & 1 & 1 & 2 & - & 1 & 2 & 30 \\
\hline \multirow{2}{*}{ Ariyalur } & S5 & 2 & 1 & 2 & 1 & 2 & 2 & 2 & 2 & 2 & - & 1 & 2 & 2 & 3 & - & - & 24 \\
\hline & S6 & 3 & 2 & 2 & 2 & 1 & 1 & - & - & 1 & 1 & - & - & 1 & - & - & - & 14 \\
\hline \multirow{2}{*}{ Pudukkottai } & S7 & 2 & 1 & 2 & 2 & 3 & - & 1 & 1 & 2 & - & 1 & 1 & 2 & - & 1 & - & 19 \\
\hline & S8 & - & 2 & 1 & 1 & - & 2 & 1 & 1 & - & 1 & 2 & 3 & 2 & - & - & - & 16 \\
\hline \multicolumn{2}{|l|}{ Total } & 13 & 15 & 20 & 12 & 14 & 11 & 9 & 10 & 16 & 8 & 7 & 11 & 16 & 9 & 6 & 4 & 181 \\
\hline \multicolumn{2}{|c|}{$\%$ contribution } & $\begin{array}{c}7.1 \\
8\end{array}$ & $\begin{array}{c}8.2 \\
8\end{array}$ & $\begin{array}{c}11.0 \\
4\end{array}$ & $\begin{array}{c}6.6 \\
2\end{array}$ & $\begin{array}{c}7.7 \\
3\end{array}$ & $\begin{array}{c}6.0 \\
7\end{array}$ & $\begin{array}{l}4 . \\
9\end{array}$ & $\begin{array}{c}5.5 \\
2\end{array}$ & $\begin{array}{c}8.8 \\
3\end{array}$ & $\begin{array}{c}4.4 \\
1\end{array}$ & $\begin{array}{c}3.8 \\
6\end{array}$ & $\begin{array}{c}6.0 \\
7\end{array}$ & $\begin{array}{c}8.8 \\
3\end{array}$ & $\begin{array}{l}4 . \\
9\end{array}$ & $\begin{array}{c}3.3 \\
1\end{array}$ & 2.2 & \\
\hline
\end{tabular}

Table.3 Percent contribution of fungal species in different tomato fields

\begin{tabular}{|c|l|c|c|c|c|c|c|c|c|}
\hline \multirow{2}{*}{$\begin{array}{c}\text { S. } \\
\text { No }\end{array}$} & \multirow{2}{*}{ Fungal Species obtained } & \multicolumn{9}{|c|}{ \% Contribution } \\
\cline { 2 - 11 } & & S1 & S 2 & S 3 & S 4 & S 5 & S 6 & S 7 & S8 \\
\hline 1 & Aspergillus flavus & 3.5 & 8.6 & 3.7 & 6.7 & 8.33 & $\mathbf{2 1 . 4 3}$ & 10.53 & - \\
\hline 2 & Aspergillus fumigatus & 10.71 & - & 7.4 & $\mathbf{1 3 . 3 3}$ & 4.17 & 14.28 & 5.26 & 12.5 \\
\hline 3 & Aspergillus niger & $\mathbf{1 7 . 8 6}$ & 8.6 & 11.11 & 10 & 8.33 & 14.28 & 10.53 & 6.25 \\
\hline 4 & Aspergillus sydowii & 7.1 & 4.3 & 3.7 & 6.7 & 4.17 & 14.28 & 10.53 & 6.25 \\
\hline 5 & Aspegillus terreus & 3.5 & 8.6 & 11.11 & 6.7 & 8.33 & 7.14 & $\mathbf{1 5 . 7 9}$ & ----- \\
\hline 6 & Aspergilllus versicolor & 7.1 & 4.3 & 3.7 & 6.7 & 8.33 & 7.14 & - & 12.5 \\
\hline 7 & Aspergillus sulphureus & 3.5 & 8.6 & - & 6.7 & 8.33 & - & 5.26 & 6.25 \\
\hline 8 & Aspergillus candidus & 7.1 & 4.3 & 3.7 & 6.7 & 8.33 & - & 5.26 & 6.25 \\
\hline 9 & Penicillum chrysogenum & 7.1 & $\mathbf{1 7 . 4}$ & 11.11 & 6.7 & 8.33 & 7.14 & 10.53 & - \\
\hline 10 & Penicillum citrinum & 3.5 & 8.6 & 3.7 & 6.7 & - & 7.14 & - & 6.25 \\
\hline 11 & Penicillium frequestans & 3.5 & 4.3 & - & 3.33 & 4.17 & - & 5.26 & 12.5 \\
\hline 12 & Penicillium notatum & 3.5 & 4.3 & 7.4 & 3.33 & 8.33 & - & 5.26 & $\mathbf{1 8 . 7 5}$ \\
\hline 13 & Curvularia lunata & 3.5 & 4.3 & 7.4 & 3.33 & - & 7.14 & 5.26 & - \\
\hline 14 & Rhizopus stolanifer & 7.1 & 8.6 & 7.4 & - & $\mathbf{1 2 . 5}$ & - & - & - \\
\hline 15 & Mucor sp. & 7.1 & 4.3 & $\mathbf{1 4 . 8 1}$ & 6.7 & 8.33 & - & 10.53 & 12.5 \\
\hline 16 & Terchoderma viridi & 3.5 & - & 3.7 & 6.7 & - & - & - & - \\
\hline
\end{tabular}


Table.4 Physicochemical parameter of soil samples from different tomato fields.

\begin{tabular}{|c|l|c|c|c|c|c|c|c|c|}
\hline \multirow{2}{*}{$\begin{array}{c}\text { S. } \\
\text { No. }\end{array}$} & \multicolumn{1}{|c|}{ Samples } & S1 & S2 & S3 & S4 & S5 & S6 & S7 & S8 \\
\cline { 2 - 10 } & $\mathbf{p H}$ & 7.0 & 7.9 & 6.3 & 7.3 & 7.3 & 7.5 & 6.8 & 7.3 \\
\hline $\mathbf{2}$ & Soil Salinity & 0.45 & 0.73 & 0.39 & 0.40 & 0.83 & 0.20 & 0.77 & 0.81 \\
\hline $\mathbf{3}$ & Soil Colour & Red Soil & Gray & $\begin{array}{c}\text { Black } \\
\text { Soil }\end{array}$ & $\begin{array}{c}\text { Red } \\
\text { Soil }\end{array}$ & Gray & Gray & Red Soil & Gray \\
\hline $\mathbf{4}$ & Soil texture & Sandy-loam & $\begin{array}{c}\text { Sandy- } \\
\text { clay }\end{array}$ & $\begin{array}{c}\text { Sandy- } \\
\text { clay }\end{array}$ & Sandy & $\begin{array}{c}\text { Sandy- } \\
\text { clay }\end{array}$ & Sandy & $\begin{array}{c}\text { Sandy- } \\
\text { clay }\end{array}$ & Sandy \\
\hline $\mathbf{5}$ & $\begin{array}{l}\text { Organic Carbon } \\
\text { (OC\%) }\end{array}$ & 0.71 & 0.59 & 0.81 & 0.96 & 0.68 & 0.08 & 0.39 & 0.18 \\
\hline $\mathbf{6}$ & Nitrogen (kg/h) & 78.8 & 67.2 & 85.2 & 94.6 & 75.6 & 37.2 & 56.4 & 43.6 \\
\hline $\mathbf{7}$ & $\begin{array}{l}\text { Phosphorus } \\
\text { (Kg/h) }\end{array}$ & 14.2 & 16.2 & 12.2 & 16.2 & 14.2 & 10.2 & 16.2 & 6.2 \\
\hline $\mathbf{8}$ & Potash (Kg/h) & 275 & 353 & 136 & 255 & 443 & 97.5 & 225 & 97.5 \\
\hline
\end{tabular}

Fig.1 Occurrence of soil mycoflora in different tomato field from various Districts of Tamilnadu.

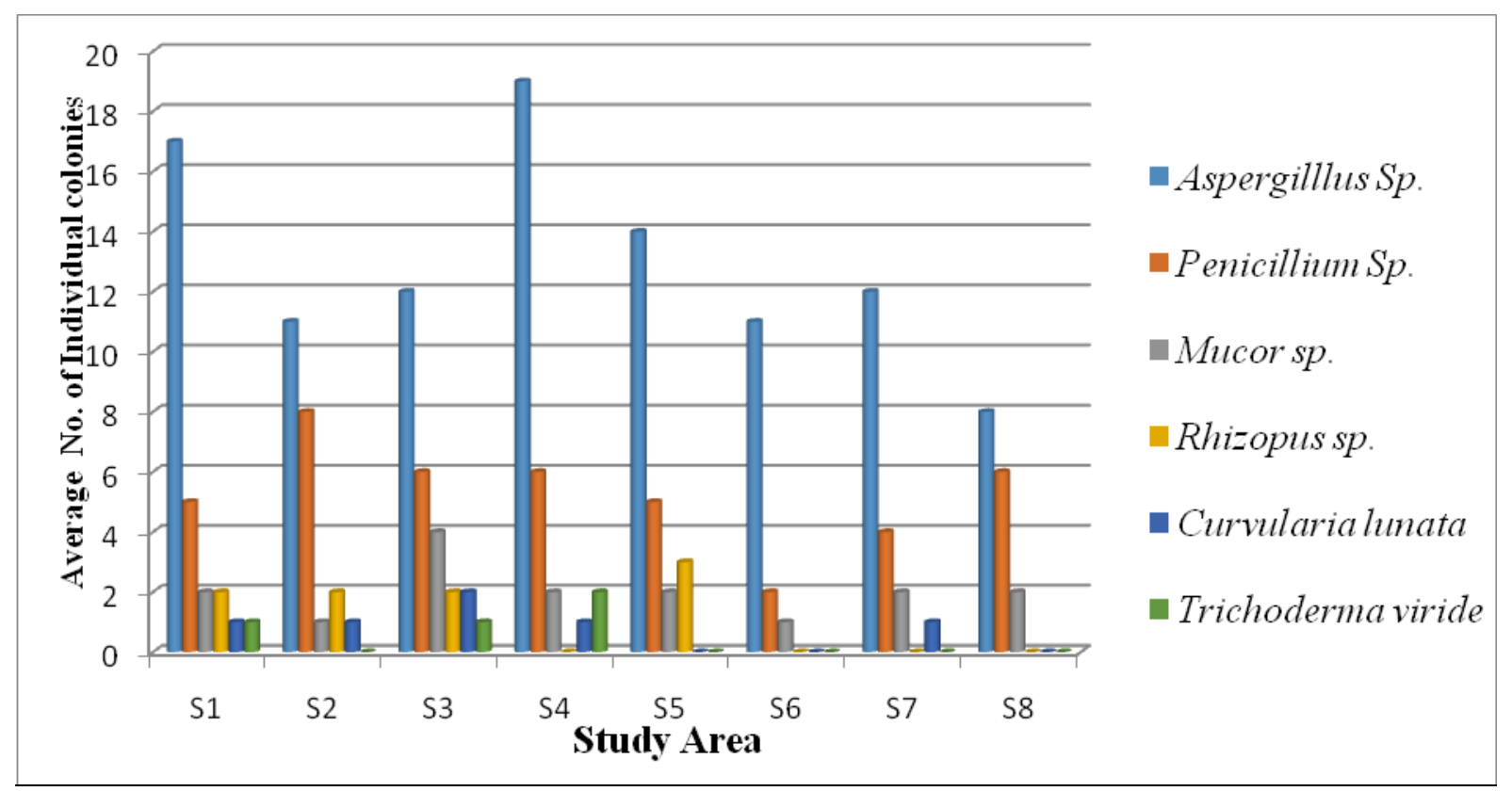


Fig.2 Fungal colonies on PDA medium.
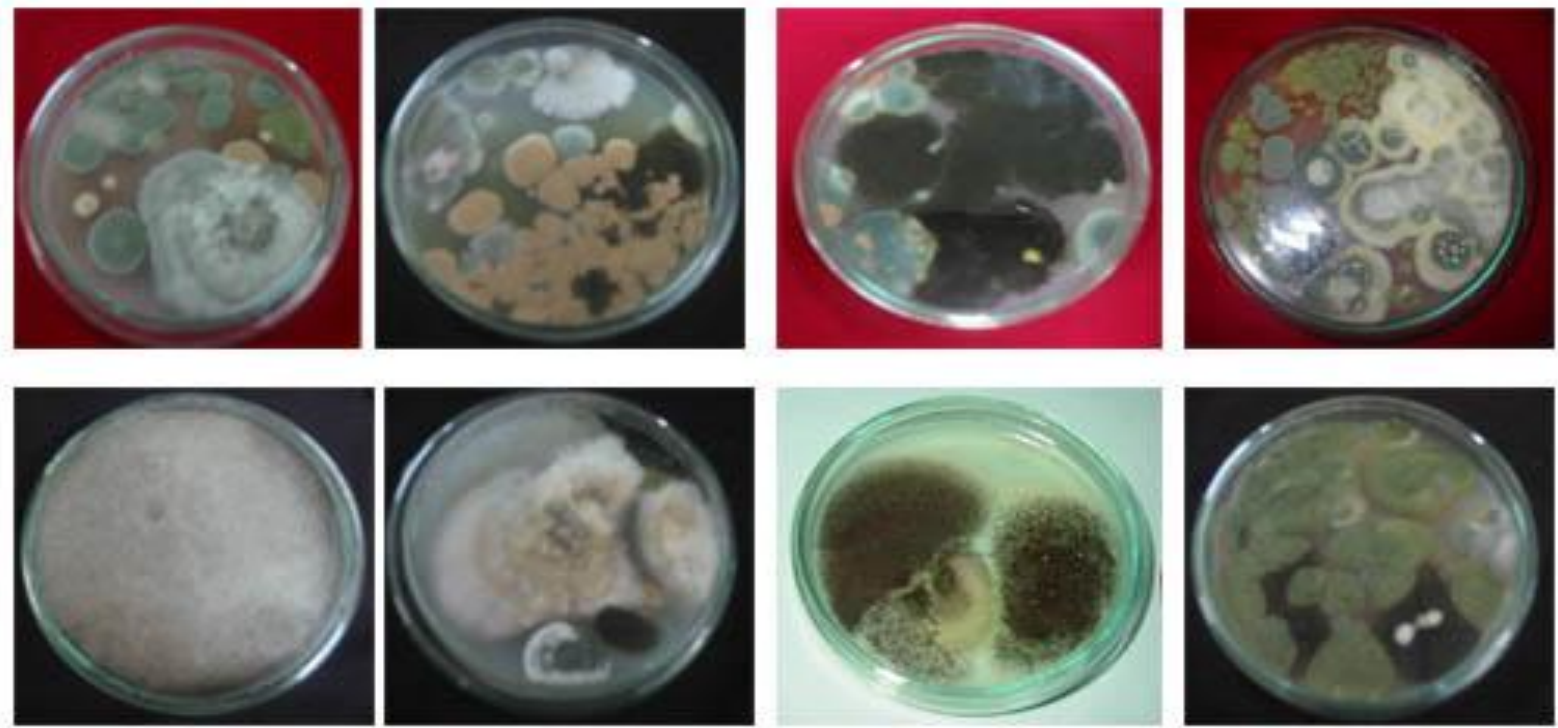

Fig.3 Pure culture on PDA medium.
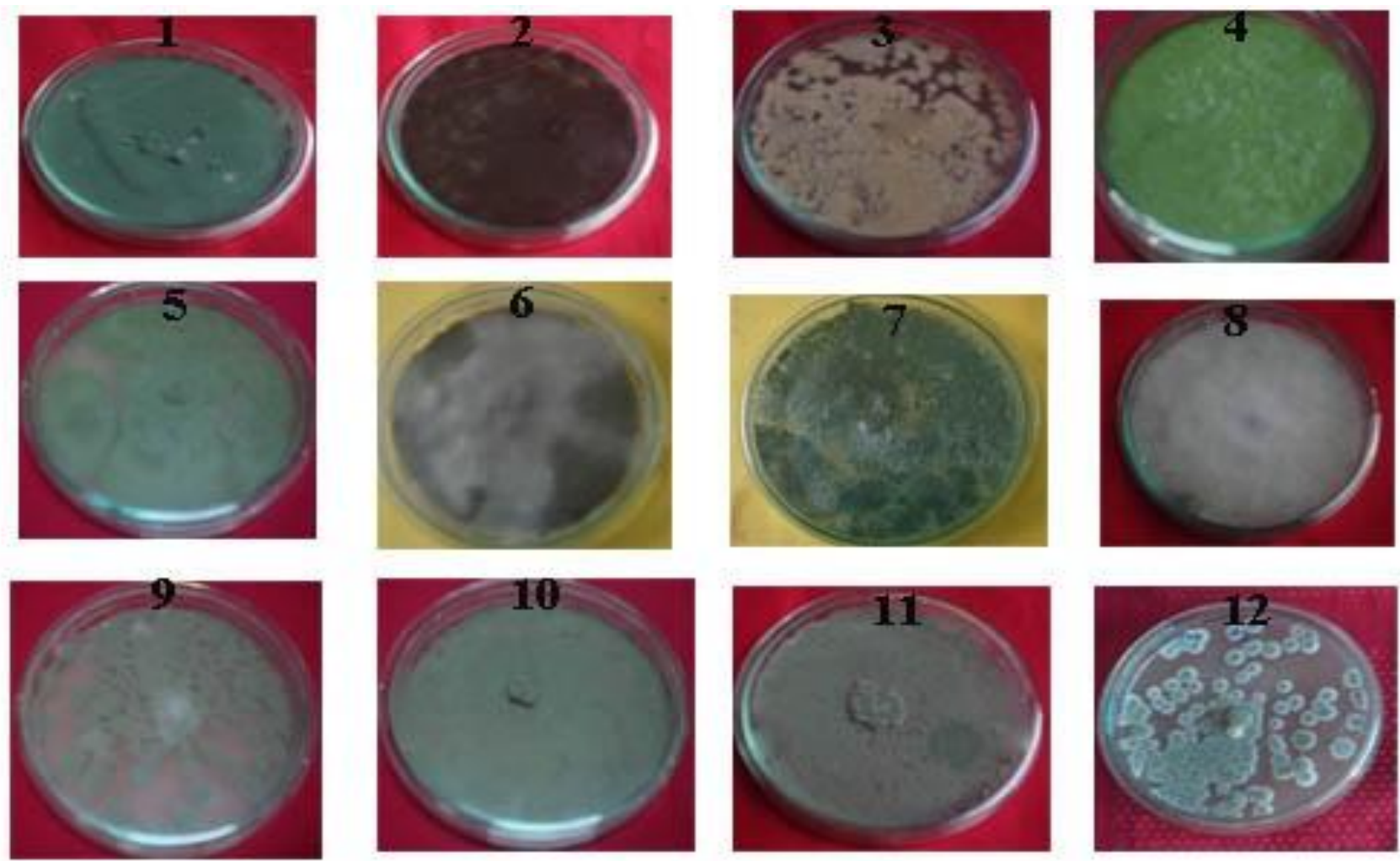

1. Aspergillus fumigatus

4. Aspergillus flavus

7. Trichoderma viridi

10. Penicillium frequestans
2. Aspergillus niger

5. Aspergillus versicolor

8. Mucor sp.

11. Penicillum citrinum
3. Aspergillus terreus

6. Curvularia lunata

9. Penicillum chrysogenum

12. Penicillum notatum 
Fig.4 Microscopic structure of Isolated soil Fungi.
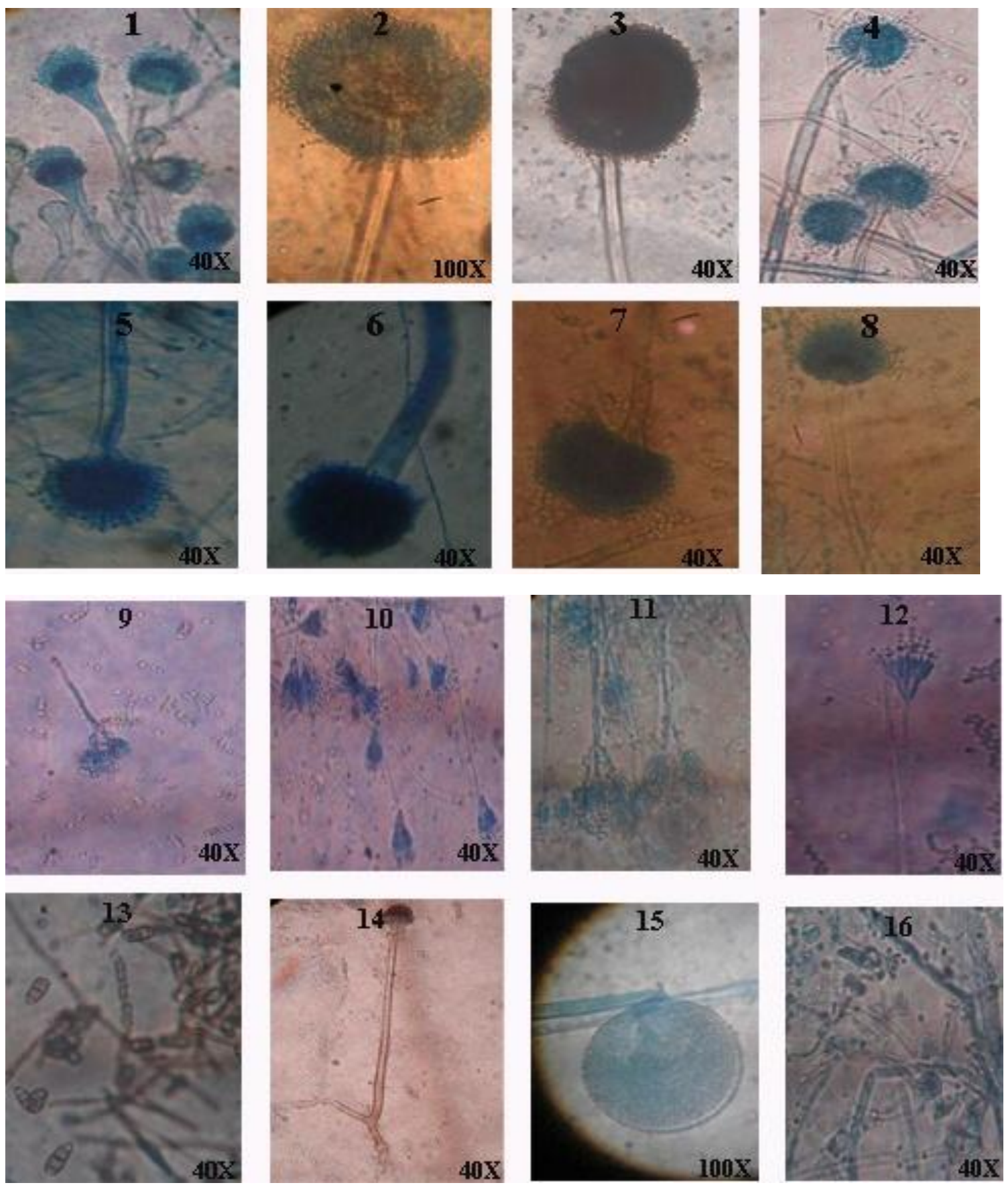

1. Aspergillus flavus

5. A. terreus

2. A. fumigatus

6. A. versicolor

3. A. niger

7. A. sulphureus

4. A. sydowii

9. Penicillium chrysogenum

10. P. citrinum

11. P. frequestans

8. A. candidus

12. P. notatum

14. Rhizopus stolanifer 15. Mucor sp. 
The soil pH, organic content and water are the main factors affecting the fungal population and diversity (Zhang et al., 2001). The Organic carbon, nitrogen, phosphorus, potassium are important for fungi. In the absence of any of these the growth and sporulation of moulds as well as other microorganisms are hampered a lot .It has been reported that the density of fungal population occurred during the monsoon (rainy) season when the soil moisture was significantly high (Table-4).

In conclusion, in the present study eight different tomato field soil samples of four districts were studied for screening and detected of fungal diversity. Aspergillus, Penicillium and Mucor species were dominant in all tomato fields due to the high sporulation capacity and the Penicillium sp. were producing fungal and bacterial antibiotics and the Aspergillus sp. producing different kinds of toxins. These toxins may prevent the growth of other fungal species. The frequency of mycoflora in tomato fields were found to be regulated by many factors like temperature, $\mathrm{pH}$, soil salinity, soil texture, organic carbon and inorganic materials.

\section{References}

Ainsworth, G.C, G.R. Bisby. 1995. Dictionary of the Fungi eight edition. Common Wealth Mycological Institute Kew, Surrey PP 445.
Arunachalam, K., Arunachalam, R.S Tripathi and Pandey. H .N, 1997. Trop. Ecol., 38: 333 - 341.

Chiang, C.N., Soudi, B. 1994. Biologie du sol et cycles biogeochimiques. In: El Hassani TA. And Persoon E (Eds), Agronomie Moderne, Bases physiologiques et agronomiques de la production vegetale, $85-118 \mathrm{pp}$.

Gilman, J.C. 2001. A Manual of Soil fungus, 2nd Indian edition, Biotech Books, Delhi.

Kiran Singh, Jaishree Borana, sobha Srivastava, V.A. 1999. J. Soil Biol. Ecol., 19: 11-14.

Mc. Gill, W.B., Cannon, K.R., Robertson, J.A., Cook, F.D. 1980. Canadian J. soil Sci., 66: 1-19.

Rani, C., Paneerselvam, A. 2010. Fungal diversity in the sediments of point calimere, East coast of India. J. Pure Appl. Microbiol., 4: 1999-2006.

Sylvia, D.M., Fuhrmann, J., Hartel, P., Zuberer, D.A. 2005. Principles and Applications of Soil Microbiology: Upper Saddle River, NJ, Prentice Hall, p. 408-426.

Warcup, J.H. 1955. On the origin of colonies of fungi developing on soil dilution plates, Trans. Brit. Mycol. Soc., 38: 298-301.

Zhang, C.B., Jin, Z.X., Li, J.M. 2001. Diversity of bacterial physiological groups and microbial flora in the soil of eight forest types of Tiantai Mountain, Zhejiang, Biodiversity Sci., 9(4): 382-388.

\section{How to cite this article:}

Paulina Fatima Mary, A., and Sagaya Giri R. 2016. Studies on Soil Mycoflora in Different Tomato fields of Four Districts in Tamilnadu, India. Int.J.Curr.Microbiol.App.Sci. 5(7): 92-99. doi: http://dx.doi.org/10.20546/ijcmas.2016.507.007 